REVISTA CHILENA DE LITERATURA

Noviembre 2009, Número 75, 91 - 114

\title{
DOS MIRADAS A LA GUERRA EN LA POESÍA DE TOMÁS HARRIS ${ }^{1}$
}

\author{
Mary Mac-Millan \\ Universidad Adolfo Ibáñez \\ mary.macmillan@uai.cl
}

RESUMEN / ABSTRACT

El presente trabajo se centra en el acontecimiento traumático de la guerra, la posibilidad del sujeto de realizar una experiencia y sostenerse en cuanto tal, pese a la anulación que recae sobre él. El análisis se lleva a cabo en dos poemarios del poeta chileno Tomás Harris: "Encuentros al fin de la batalla" (de Encuentros con hombres oscuros) y "Balada del soldado de Oklahoma" (de Tridente). Ambos poemarios entran en diálogo y choque, puesto que uno aborda la Segunda Guerra Mundial y el segundo la guerra mediática del Golfo. La poesía pone a prueba sus propias posibilidades y nos muestra un sujeto que oscila entre el duelo y la melancolía y que se niega a ser reducido a un mero espectador pasivo.

PALABRAS ClAVE: guerra, duelo, melancolía, sujeto, Harris.

This article aims at exploring the possibility of surviving and realizing an experience from the traumatic event of war. The analysis is focused on two works by the Chilean poet Tomás Harris: "Encuentros al fin de la batalla" of Encuentros con hombres oscuros and "Balada del soldado de Oklahoma" of Tridente. Both poems are related to the issue of war trauma: in the first work, it approaches World War II and the second, the mediatic Gulf War. Thus, the poetry of Harris questions its own limits by means of a subject who oscillates between mourning and melancholy, and rejects to be reduced to a mere passive spectator.

KEY WORDS: war, mourning, melancholy, subject, Harris.

1 Este trabajo es parte del proyecto de investigación Fondecyt $\mathrm{N}^{\circ} 11075019$, titulado Constitución de un sujeto sobreviviente en la poesía de Tomás Harris: Trauma, Cuerpo y Narración. 
Abordaremos en este análisis el acontecimiento traumático de la guerra y su despliegue en la poesía de Tomás Harris ${ }^{2}$. Nos interesan los recursos de la escritura para transmitir dicha experiencia y la posibilidad de advenimiento de un sujeto determinado. Para ello hemos escogido dos poemarios que entran en directo diálogo confrontacional. Son dos posturas distintas frente al trauma de la guerra: "Encuentros al fin de la batalla" de Encuentros con hombres oscuros y "Balada del condenado de Oklahoma" de Tridente.

\section{1. "ENCUENTROS AL FIN DE LA BATALLA": ENTRE EL DUELO Y LA MELANCOLÍA}

El conjunto de poemas destaca y asombra por apartarse de la estética más obscena que domina el resto de la obra de Harris. Prima un tono bucólico, con un suave lirismo que evoca estados anímicos cercanos a la melancolía. El poemario tiene como eje conductor escenas de la Segunda Guerra Mundial, guerra que según Harris: "aún se huele a la distancia" (Encuentro 88). Los poemas son breves cuadros que dan fragmentadamente aristas de una compleja realidad. Son las experiencias de un joven soldado alemán concentradas en dieciséis poemas que nos relatan desde la amistad con un compañero moribundo, el salto en paracaídas sobre territorio enemigo, hasta el regreso a casa. Nos centraremos en el tono que subyace a todas las experiencias mencionadas. Hay en ellas elementos que las asemejan tanto al duelo como a la melancolía. Nos proponemos mostrar la presencia de ambos como un modo de elaborar ${ }^{3}$ el trauma de la guerra.

2 Tomás Harris (1956, La Serena) se ubica dentro de la generación del setenta y cuenta con una vasta producción poética, la que consta hasta el momento de los siguientes poemarios: Zonas de peligro (1985), Diario de navegación (1986), El último viaje (1987), Alguien que se sueña, Madame (1986), Cipango (1992), Noche de brujas y otros hechos de sangre (1993), Los siete náufragos (1995), Crónicas maravillosas (1997), Encuentro con hombres oscuros (2001), Ítaca (2001), Tridente (2005) y Lobo (2007). A esto se le suma Veinticinco Años de Poesía Chilena (1970-1995) e Historia personal del miedo (1994) (cuentos). Ha sido reconocido con los siguientes premios: Premio Municipal de Poesía 1993 por Cipango, Premio del Consejo del Libro y la Lectura 1993 por Los siete náufragos, Premio Pablo Neruda en 1995, Premio Casa de las Américas en 1996 por Crónicas Maravillosas y finalista del Premio Altazor con Encuentros con hombres oscuros el 2001.

${ }^{3}$ En este tema seguimos los postulados de Dominick LaCapra en Escribir la Historia, Escribir el trauma. Según LaCapra el sujeto que padece una experiencia traumática responde 
Según Freud “(e)l duelo es, por regla general, la reacción frente a la pérdida de una persona amada o de una abstracción que haga sus veces, como la patria, la libertad, un ideal, etc." (Freud 241). Nuestra lectura apunta a definir la experiencia ${ }^{4}$ de la guerra como una experiencia de "pérdida". Es ésta la que origina la respuesta ya sea del duelo (elaboración) o de la melancolía (reactuación). Ahora bien, el "objeto" perdido, en el caso de la guerra,

según dos posibilidades, las que generan matices o múltiples etapas intermedias: la reactuación (acting out) y la elaboración. Estas distinciones no son concebidas como binarias sino como procesos que interactúan (86). Lo central aquí es cuánto ha podido el sujeto asimilar el acontecimiento traumático. De esto se desprenderá una determinada noción de historia o de temporalidad. Es decir, la mayor o menor elaboración permitirá constatar un sujeto abierto al futuro y, por ende, con capacidad para seguir elaborando su historia o, por el contrario, un sujeto que tiende más bien a la repetición. Precisamos estos conceptos. Reactuación o acting out: "en el acting out los tiempos hacen implosión, como si uno estuviera de nuevo en el pasado viviendo otra vez la escena traumática. Cualquier dualidad (o doble inscripción) del tiempo (pasado y presente o futuro) se derrumba en la experiencia o solo produce aporías y dobles vínculos. En este sentido, la aporía y el doble vínculo pueden contemplarse como indicio de un trauma que no ha sido elaborado" (46).

Elaboración: "los procesos de elaboración, entre los cuales está el duelo y los distintos modos de pensamiento y quehacer crítico, entrañan la posibilidad de establecer distinciones o desarrollar articulaciones que, aunque reconocidas como problemáticas, funcionan como límites y posible resistencia a la indecibilidad" (46).

4 Lo que parece estar en juego en ambos poemarios de Harris es precisamente el estatuto de "experiencia" de determinados acontecimientos, en este caso específico, la guerra. Siguiendo a LaCapra, destacamos el vínculo explícito entre trauma, experiencia e identidad: "El trauma es una experiencia que trastorna, desarticula el yo y genera huecos en la existencia; tiene efectos tardíos imposibles de controlar si no con dificultad y, tal vez, imposibles de dominar plenamente" (Escribir 63). La noción de "experiencia" aplicada al trauma generará un cuestionamiento, puesto que LaCapra debate el estatuto de experiencia para los acontecimientos traumáticos. Hay una cierta paradoja en todo trauma que implicaría una especie de desplazamiento temporal y del sujeto mismo en relación con lo "experimentado". Esta paradoja se observa con claridad en la siguiente cita en la que LaCapra sigue a Freud: "el trauma está 'en' la repetición de un suceso anterior en un suceso posterior, suceso anterior que ocurrió cuando uno no estaba preparado para sentir angustia y suceso posterior que de algún modo evoca el previo y dispara así la respuesta traumática" (100). Se observa pues la escisión del sujeto que genera el acontecimiento sui generis, desintegración tal que por lo mismo genera el debate si el trauma es posible o no de ser considerado como una "experiencia": "El trauma es en sí mismo una experiencia perturbadora que irrumpe -en- o incluso amenaza destruir la experiencia, en el sentido de vida integrada o al menos articulada de una manera viable. Hay un sentido en que el trauma es una experiencia fuera -de- contexto que perturba las expectativas y desestabiliza la comprensión de los contextos existentes" (Historia 161-62). 
es difícil de precisar y se desplaza constantemente, lo que induce hacia la melancolía. Puede ser la familia, la infancia, la casa, la nación u "objetos" más vagos como la pureza, la naturaleza, la idealización. Todos estos objetos circulan en los poemas de Harris bajo un sello de degradación, lo que en definitiva nos permite pensar que lo "perdido", y que da origen al duelo, más que algo concreto, es un "modo de vincularse con los objetos". Estos se vuelven extraños y sufren cambios que le hacen perder el vínculo. Es por esta especial condición del "objeto perdido" que los poemas tienden más hacia la melancolía que al duelo, puesto que la restitución de lo perdido resulta mucho más compleja que en la pérdida de un ser querido. La pérdida entendida como un "modo de relacionarse" con el mundo arroja necesariamente una pérdida del sujeto. Es decir, no solo se pierden los "objetos" (casa, familiares, naturaleza, etc.) sino, también el mismo sujeto que padece la pérdida. Más aún, en la medida en que lo perdido llega a los límites de un concepto tan amplio como nación e incluso una idea de occidente y de Europa, el sujeto que padece el duelo o la melancolía no es solo el joven soldado que regresa de la guerra ${ }^{5}$, sino que se generaliza. El trauma de la guerra sobrepasa, sobre todo en los últimos poemas, la experiencia límite de un sujeto determinado (el soldado Erwin Kopp), y se convierte en la de toda una cultura: la europea. La naturaleza, entendida como cultura, jugará aquí un rol central. Por otro lado, la abundante referencia a motivos propios de la poesía y del paisaje cultural de Europa nos permiten esta lectura generalizada del trauma que sobrepasa al individuo: los cuervos, los ríos, los olmos, etc.

Antes de entrar de lleno en los poemas, es necesario precisar la distinción entre duelo y melancolía. Ambas respuestas a la experiencia traumática comparten casi los mismos rasgos: "talante dolido, pérdida del interés por el mundo exterior - en todo lo que no recuerde al muerto-, la pérdida de la

5 Pareciera haber en todo este poemario un interlocutor oculto, nos referimos a Walter Benjamin y su conocida sentencia: "Entonces se pudo constatar que las gentes volvían mudas del campo de batalla. No enriquecidas, sino más pobres en cuanto a experiencia comunicable" (Discursos 167). Precisamente lo que está en juego en este análisis es el estatuto de "experiencia" para el trauma de la guerra. Nos son de ayuda aquí las distinciones etimológicas entre Erlebnis y Erfahrung: "Erlebnis es una 'experiencia no integrada' y Erfahrung es una 'experiencia relativamente integrada', vinculada con procedimientos tales como la narración o el relato de historias" (LaCapra, Historia 82). El yo de "Encuentros al fin de la batalla" busca en la palabra un medio para integrar una experiencia traumática en sí irreductible. Nuestra lectura apunta a mostrar, más que un éxito, un proceso que oscila constantemente. 
capacidad de escoger algún nuevo objeto de amor (...), el extrañamiento respecto de cualquier trabajo productivo que no tenga relación con la memoria del muerto" (Freud 242). Freud describe el duelo como un trabajo en el que el sujeto no desea desprenderse del "objeto perdido" que le genera dolor. Aunque lo amado ya no esté más allí, el sujeto actúa como si estuviera. Con el tiempo ocurre un "acatamiento a la realidad": "la orden que esta imparte no puede cumplirse enseguida. Se ejecuta pieza por pieza con una gran gasto de tiempo y energía de investidura, y entretanto la existencia del objeto perdido continúa en lo psíquico" (242-243). Veamos cuál es la diferencia entre duelo y melancolía. Un punto central es que en la melancolía, el sujeto no perfila tan nítidamente el objeto de su pérdida como en el duelo, porque la pérdida es "de naturaleza más ideal": "El objeto tal vez no está realmente muerto, pero se perdió como objeto de amor (...).Y en otras circunstancias nos creemos autorizados a suponer una pérdida así, pero no atinamos a discernir con precisión lo que se perdió" (243). Esto lleva al sujeto a incertidumbres del tipo "sabe a quién perdió, pero no lo que perdió en él". Junto a esta poca claridad en cuanto a la pérdida, la melancolía se distingue del duelo además por el sentimiento de disminución del yo o, como Freud señala, un "empobrecimiento del yo": "En el duelo, el mundo se ha hecho pobre y vacío; en la melancolía, eso le ocurre al yo mismo" (243). Intentaremos a continuación precisar en qué consiste la pérdida que origina el duelo y la melancolía en los poemas escogidos.

A lo largo de los dieciséis poemas que componen "Encuentros al fin de la batalla", se observa una clara presencia de la naturaleza. Ésta adquiere estatuto de "paisaje", ya que es el espacio en el que se desenvuelve la cultura europea. Por ejemplo, decir Danubio no es solamente la mención a un "río", mera naturaleza, sino Alemania, Austria, una cierta noción de pertenencia y de nación que va más allá de la mera geografía. Así es como dos jóvenes soldados intentan sustraerse a la batalla y a la muerte conversando de "cosas sin importancia": "Hablamos de cosas sin importancia/ciudades, parientes, el frío en Bavaria/ y recuerdos en distintos lugares y colores del rumbo del Danubio" (89). El paisaje como sinécdoque de Europa aparece en variadas expresiones: en sus espacios abiertos (bosques, sotobosques, colinas, ríos); en la mención a animales o aves (cuervo, cornejas); y en árboles (olmo) y flores (asfódelos). El paisaje no es mero telón de fondo para los acontecimientos. Ciertamente, el cambio originado por la guerra acontece en el paisaje, pero con ello involucra una idea de nación y de cultura europea. A este fuerte rol de la naturaleza-paisaje se van ligando pensadores alemanes que se ven 
afectados en la catástrofe de la guerra: Nietzsche, Wagner, Hegel, Trakl. Es decir, el duelo que estamos tratando de precisar involucra tanto al paisaje como a los portavoces de la cultura alemana. Por eso, la pérdida que origina el luto es también la de la identidad del sujeto. El sujeto no es solo un soldado quinceañero, sino uno alemán y europeo. Mostraremos esta conjunción entre paisaje-cultura y pérdida producto de la guerra.

En las tres versiones de "Regreso a Casa" se observa el cambio sufrido en el "paisaje" luego de la guerra. Este cambio es siempre una merma, es decir, una transformación negativa que dificulta el regreso a lo cotidiano, al hogar, puesto que ese lugar ya no existe: "el ruido de la frondosidad de los olmos/cuando todavía no los habíamos talado" (92). La tala de los olmos no es un mera pérdida en la naturaleza, ya que esos "olmos" se leen, insisto, como un elemento cultural, como se constata en los versos posteriores: "Hegel envejece dialécticamente bajo los olmos/esta tarde convaleciente de guerra" (102). Es decir, los olmos actúan simbólicamente "en lugar de". Puede ser "protección", "sombra" o "pensamiento", como lo sugiere la mención a uno de los principales pensadores alemanes. Los "olmos talados" son así parte de un patrimonio que se ve mermado.

Volviendo al poema de "Regreso a Casa", hay una segunda mención al "paisaje", esta vez a las flores: "miro todo lo que alcance el radio de la lumbre:/ los asfódelos ensombrecidos" (92). Los asfódelos están ligados tradicionalmente a ceremonias fúnebres y preceden a los versos finales en los que se observa un sujeto disminuido en su yo, típico de los estados melancólicos: "rata negra cambiemos de piel,/yo te regalo mis viejas prendas y tú me das tu inmortal inconsciencia" (92). Es decir, el yo se anula y se rebaja al estatus de una rata, lo que se condice con la pérdida en el paisaje. Más alusiones a éste se leen en la segunda versión: "no quiero hablar de la sustitución de las flores por el barro (...). Pero yo vi el río seco, o vi sangre en lugar de la cotidiana agua verde de su curso, y un temblor en la rivera" (93). La conexión entre paisaje-cultura y la pérdida se observa más claramente en el poema "Meditación sobre una colina yerma" (95). El poema tiene como eje la destrucción total de la abadía de Montecasino el año 1944 por los norteamericanos. La abadía es más que un edificio en una colina al sur de Roma. El monasterio y su entorno son parte de la historia europea y eso es lo que destruyen los bombarderos: "hubo que bombardear el convento, lástima/dijeron los Yankees mascando su tabaco amargo" (95). La locura de destruir un centro cultural y religioso se ve exacerbada mediante el contrapunto que Harris realiza entre los personajes del "tarot marsellés" y la escena de la 
colina italiana. Las cartas del tarot representan un orden mediante sus personajes: el loco, el colgado, etc. El frote entre el "orden" del tarot y la escena de la guerra origina un cuestionamiento de la realidad: "El Loco del Tarot marsellés ${ }^{6}$ no es/lo mismo que la aparición del sol/sobre las colinas yermas y atormentadas/por una guerra que se extendió/más allá de las mesas de verde cubierta" (95). Hay un salto metaléptico desde la mesa del juego a la realidad, donde la comparación prosigue marcada por los deícticos "allí, para las cartas, y "ahí", para Montecasino: "allí, las cartas desparramadas del mazo/pueden mostrar todos sus símbolos,/el colgado, la muerte, la torre, el mismo loco: en las colinas yermas de Montecasino no es/ nada igual, a pesar de su exasperante/repetición en el paisaje de ruinas" (95). El contrapunto entre la "simbología" de las cartas y la realidad del paisaje ruinoso sugiere una pérdida de sentido que en el mundo ordenado de las cartas prevalece, mas no así en el de la guerra, donde se da una inversión: "el colgado, ahí, cuelga de un árbol mustio, la muerte es la sombra que opaca el otrora esplendor/ de la torre abolida, y el loco merodea/ entre los cadáveres y los huesos/tomándose con las dos manos la cabeza,/antes que el sol se oculte y las sombras/ se tomen de la mano con la muerte/ y bailen su vals demente"(95). Nada tienen que ver el alegre y bufonesco loco del tarot con la locura que se ha apoderado en las colinas yermas: no solo se ha destruido un edificio emblemático sino un modo de entender la muerte. Es el propio loco quien se toma la cabeza con las dos manos en señal de que ahora sí una locura mayúscula ha advenido. Lo que ocurre es que el estado en que queda el paisaje, entendido siempre como cultura y civilización, es el de la ruina. Ésta engloba tanto al paisaje como al sujeto, uniendo así indisolublemente el destino de una nación con el del sujeto. El soldado que vuelve y encuentra todo cambiado dice: "Dudo si quedarme aquí de pie,/eternamente tal vez o hasta que muera de ruina"7 (94). Este paisaje degradado actúa como isotopía

6 Esta carta representa la figura de un despreocupado joven caminando sin rumbo con un hatillo en las espaldas, es señal de creatividad y libertad. Aparece también un sol que lo alumbra como único guía.

7 Una vez más pareciera que Benjamin aflora como intertexto en este poemario, sin embargo, en relación con el concepto de ruina, creemos que hay diferencias entre la concepción de Benjamin y el tratamiento harriano. En el breve fragmento sobre el Angelus Novus (La dialéctica del suspenso) el ángel de la historia tiene su rostro vuelto hacia el pasado y "ve una sola catástrofe, que incesantemente apila ruina sobre ruina y se las arroja a sus pies" (54). Reconocemos los rasgos de la melancolía: la fijación con el pasado y su concepción 
a lo largo de todo el poemario. Las mismas "colinas yermas" de Montecasino reaparecen en otro contexto en el poema "La involución de los pueblos": "En silencio sobre la fosa /miro la extensión de colinas yermas/ y las manchitas azulinas de los campesinos/ absortos en la recolección de no sé qué/ tesoros ignorados entre la breza de marzo;/¿nos volveremos, como nuestros despreciados/ y reales antepasados, un pueblo recolector?: ¿de derrotas, de ladrillos rotos, de castañas amargas?" (98). El sujeto habla por un nosotros que en el contexto se lee como el pueblo alemán derrotado. El primer verso sitúa al yo desde la muerte en un estado de duelo ("en silencio sobre la fosa"). Esa muerte concreta de personas se traslada en un segundo momento al paisaje, mediante el adjetivo "yermas" para las colinas. Y en un tercer momento, la muerte, que ya ha pasado desde el sujeto al paisaje, se hace extensiva ahora a la nación mediante la definición de "recolectores de derrotas", "ladrillos rotos" y de "castañas amargas". Nuevamente la naturaleza se equipara a la cultura al ubicarse en un mismo sintagma tanto los "ladrillos" (edificación) como las "castañas amargas" (naturaleza). Es decir, el duelo abarca tanto al sujeto como a todo lo que lo rodea y a lo que pertenece: una nación. Por eso es que prima la melancolía por sobre el duelo: hay una rebaja en el yo, una pérdida que le compete al yo disminuido en la derrota. En "Tiempo de muerte" se lee nuevamente este estado dolido. El hablante se encuentra en pleno proceso de duelo, ya que, por un lado, está apegado a sus muertos -como fijado a esos objetos- pero, por otro, inicia un proceso o trabajo de despedida: "Serpientes y viejas cornejas se pasean por la tarde/del primer otoño después de la guerra" (100). Hay una incipiente distancia temporal que permite la elaboración del duelo: "en silencio entre la fronda, ante el sotobosque, me miran y me guiñan un ojo y me ofrecen/ azúcar blanca, pan blanco, tabaco rubio" (100). Hasta aquí parece que desde la misma naturaleza herida brotara una cierta sanación que a modo de ofrenda se le alcanza al sujeto: azúcar, pan y tabaco. Se habría iniciado el duelo. Mas ahora los muertos hacen su aparición: "Eso es la hora en que converso con los muertos. /Al comienzo eran conversaciones amables, /un tanto melancólicas

de pérdida. Sin embargo, este ángel a su vez es arrastrado "hacia el futuro", de tal manera que no permanece tan solo fijado en el pasado y lo ruinoso pareciera no tocarlo. No así en el poemario en cuestión, en donde lo ruinoso no solo afecta a la historia sino también al sujeto. La ruina en Harris es un estado o relación entre un sujeto y un objeto, en que ambos se ven envueltos y mutuamente afectados. 
como las conversaciones de las tabernas/cerca de la medianoche o a los crepúsculos de los domingos" (100). Esta segunda etapa es claramente una fijación con el objeto perdido (muertos) e indica que el sujeto se halla en una etapa primaria del duelo. Una tercera etapa deja en suspenso la posibilidad de vislumbrar una mayor elaboración: "pero después los muertos se han tornado obsesivos,/bajo tierra, como están, se preguntan a cada momento/por el sol, por el mediodía;/éstos se han transformado en las palabras recurrentes/ de sus bocas llenas de tierra y muérdago: sobre todo quieren saber cuánto tiempo llevan muertos,/si acaso el sol se ha vuelto negro" (100). En esta última fase el sujeto se ve sobrepasado por las demandas de los muertos -las de no ser detenidas a tiempo, pueden sumergir al yo en la melancolía- en vez de cortar y aceptar la oferta de recomienzo que tímidamente le ofrece la naturaleza en ese guiño de los primeros versos. El sujeto, en relación con el trauma, se encuentra aún sumergido en el duelo, a medio camino entre las demandas de los muertos y una posible recuperación. En "Los cuervos de Occidente" vuelve más marcada aún la conexión entre paisaje y destino europeo: "El oro final se ofrece en ofrenda piadosa/ a mi rostro mirando las tierras de labor arrasadas/ya no por el fuego de la muerte sino/por la impotencia de las manos, que torvas/se hunden en ella como las de un padre viejo/en el vientre de una joven madre/que la vida ha desesperado en costra/ cuero, corno de caza" (103). Nuevamente se dan los desplazamientos reconocidos en los poemas anteriores: la aridez de la naturaleza es la infertilidad de las mujeres y ésta se convierte luego en la de los intelectuales alemanes: "Nietzsche y Wagner/siameses de un mismo rencor, en esta/ puesta de sol en el centro mismo de Occidente" (103). El luto entendido como infertilidad alcanza como una maldición todas las esferas a las que pueda pertenecer el sujeto dolido: la naturaleza (la tierra), la descendencia y los pensadores. Es, como se señala en el penúltimo verso, el ocaso de, el fin de algo: es la puesta de sol no solo de la naturaleza sino también de la cultura de Occidente $^{8}$.

8 Se pueden establecer aquí algunas conexiones con los postulados de Spengler en $L a$ Decadencia de Occidente. El término alemán "Untergang", de hecho, se refiere al ocaso, es decir, liga lo cultural con un fenómeno de la naturaleza, la puesta de sol. Spengler postula un pensamiento basado en las analogías y sostiene: "El medio por el cual comprendemos las formas vivientes es la analogía" (11). Su analogía base es la de reconocer en la historia procesos orgánicos: "Los conceptos fundamentales de todo lo orgánico: nacimiento, muerte, juventud, vejez, duración de la vida, ¿no tendrán también en esta esfera un sentido riguroso que nadie 
El poema se cierra con una admonición en la que nuevamente es la naturaleza la portadora del mensaje: "El cielo, puros cuervos, dementes" (103). Cabe preguntarse en este poema de duelo, ¿por qué la relativa paz o cuasi tono de bendición mística del primer verso?: "El oro final se ofrece en ofrenda piadosa/ a mi rostro". ¿Por qué el gozo del sujeto ante el fin? No cabe más que leerlo como el estado melancólico en el que se halla envuelto ${ }^{9}$, el sujeto se apega narcisísticamente a ese final que es tanto el del día como el de su destino como sujeto europeo.

Intentando responder a la pregunta por el "objeto" de la pérdida que origina estados anímicos cercanos al duelo y a la melancolía, hemos perfilado que se trata de una pérdida muy amplia y que socava la identidad del sujeto. Está ligada a la naturaleza, a la cultura y a la nación, elementos todos centrales en la identidad. Pero la pérdida abarca también espacios más íntimos, tales como la casa ${ }^{10}$, los padres, la infancia y una cierta idea de inocencia o virtud. Tres poemas nos lo muestran: "Regreso a casa", "Un recuerdo de Infancia" y "El Pecado".

En "Regreso a casa", el sujeto se encuentra doblemente solitario, al ver que ya nada ni nadie le da la bienvenida. Ha perdido a sus padres: "si Padre y Madre ya han muerto. /Deben estar sepultados en el pequeño cementerio/del pueblo/ a la orilla sur del Danubio"(93). A la pérdida paterna, es decir, de sus orígenes, se le suma la del espacio hogareño: "La casa me mira y no me reconoce”. La pérdida de la casa es básicamente la del pasado del joven. La casa es el espacio en el que realizaba sus juegos de infancia junto a su hermana y esto ya no existe. O dicho de otro modo, es él el que ha perdido su infancia. La pérdida ocasionada por la guerra es también la de una cierta inocencia o estado idílico. El poema "El Pecado" deja entrever esta situación de modo velado: "Mi padre me puso una mano en el hombro./ Me dolió mucho, lo tenía irritado, lacerado, ulcerado:/-Helga perdió el camino -me dijo- Lo

aún ha desentrañado?" (10). Este pensamiento analógico, guardando sus distancias, es el que también fundamenta la relación paisaje-cultura en los poemas de Harris.

9 Aunque también es innegable la influencia de la poesía de Trakl en este poemario.

10 La casa como espacio de seguridad e identidad la encontramos en Gastón Bachelard y La poética del espacio: "La casa en la vida del hombre suplanta contingencias, multiplica sus consejos de continuidad. Sin ella, el hombre sería un ser disperso. (...) Antes de ser "lanzado al mundo", como dicen los metafísicos rápidos, el hombre es depositado en la cuna de la casa. Y siempre, en nuestros sueños, la casa es una gran cuna" (37). 
siento, hijo" (97). La frase "perder el camino" se lee eufemísticamente como una especie de traición de la joven gracias al siguiente contrapunto: "Helga perdió el camino" pensé mirando/el hueco del segundo piso por donde cagaban los Yankees, /una mancha que mi madre y mis hermanas friegan/día a día. Esa mancha es lo peor" (97). La "mancha" dejada en el centro del hogar, espacio íntimo, indica que algo ha sido pasado a llevar. La familia entera carga con esa mancha que se le puede adjudicar a Helga, la "perdida". Si la analogía entre la mancha de la casa ocasionada por los soldados extranjeros y la de Helga aún no es evidente, los últimos versos recalcarán la ligazón: “- Helga perdió el camino,- decía mi padre,/ mientras yo miraba a mi madre pasar y pasar/un paño de agua jabonosa sobre/ la mancha de mierda que era como un pecado/sobre el piso de tablas antaño brillantes y lisas,/como era el vientre de Helga/después de bañarnos y chapotear en el río" (97). Los verbos en pretérito acentúan la ligazón, pues ni el piso ni el vientre de Helga son ya lisos y brillantes. Algo oscuro y pecaminoso se ha introducido en esta familia y los arrastra a todos. Si el pecado de Helga consiste en haberse involucrado con soldados norteamericanos, este acontecimiento cae como un estigma sobre todos: padre, madre y hermanos. El padre reacciona de modo casi catatónico y se remite a repetir una y otra vez la frase "Helga perdió el camino"; la madre, por su parte, reacciona desde su ámbito en un derroche de accionar sin sentido en la limpieza diaria. El pecado de la hermana es pues algo que no se puede borrar, un trauma que se añade al de la guerra en sí, no desaparecerá jamás y ha venido a alterar el orden reinante.

Hecho este recorrido por algunos de los poemas de "Encuentros al fin de la batalla", podemos constatar la generalización del objeto perdido: es en parte el paisaje y con ello la cultura europea que se ve mermada, son los padres y con esto la pérdida de los orígenes, es la casa o una idea de hogar ${ }^{11}$, la infancia y la pureza. El sujeto que regresa de la guerra se ve afectado en su identidad y la pérdida ocurre tanto en su exterior como en su interior. El tono de los poemas se mueve, por lo mismo, entre el duelo y la melancolía,

11 Volviendo a Bachelard y la importancia de la casa para la identidad del sujeto: "la casa natal está físicamente inscrita en nosotros. Es un grupo de costumbres orgánicas. Con veinte años de intervalo, pese a todas las escaleras anónimas, volveríamos a encontrar los reflejos de la "primera escalera", no tropezaríamos con tal peldaño un poco más alto. Todo el ser de la casa se desplegaría fiel a nuestro ser" (45). A la luz de esta cita se capta con mayor fuerza la pérdida y el trauma que despliega la poesía de Harris. 
se apega por momentos al objeto perdido en sus múltiples variaciones. La elegía y el lirismo se apoderan del sujeto. A pesar de la pérdida generalizada que lo afecta, se observa una tendencia al embellecimiento que revela una especie de vínculo narcisístico ${ }^{12}$ con lo perdido. El último poema es extremo en esta carga estética que cubre el acontecimiento con un lenguaje de delicada poesía. Esto, sobre todo, ya que el hecho es mediatizado a través de la poesía, como lo señala el título: "El soldado Erwin Kopp lee a Georg Trakl mientras sobrevuela el frente italiano". El soldado, momentos antes de saltar en paracaídas, lee a Trakl y su voz no solo se tiñe de su lenguaje, sino que asume su acción como una profecía cumplida. Trakl escribió: "Sueño y muerte, las lúgubres águilas/baten toda la noche su rumor en torno a esta cabeza" (104); y el soldado afirma: "abajo, en los otrora silenciosos campos de labor, donde los campesinos y los pastores tocaban /en sus flautas tedio y resignación, ahora,/las estrellas han descendido y fulguran desde /el barro y nosotros somos los portadores: las lúgubres águilas" (104). El soldado alemán se define mediante el verso del poeta alemán, él y los demás paracaidistas a punto de descender son las "lúgubres águilas". Si bien la definición es negativa, lo que importa aquí recalcar es el contraste entre la acción bélica en sí y el lenguaje que embellece el acontecimiento: "a qué sitio siniestro quedaré aplastado /como las mariposas nocturnas en la nariz/herrumbrosa de nuestro avión?" (104). Otro ejemplo de este marcado "lirismo": "Pronto caeremos al rojo follaje de bombas sonoro". La opción por transmitir los crudos hechos bélicos mediante esta estetización indica, como ya decíamos, una ligazón de tipo narcisista. Si bien el sujeto se ve mermado en esta guerra, se aferra a ella mediante el lenguaje. La narración se constituye de algún modo en una elaboración que salva al sujeto de la desaparición total. Hay experiencia y su transmisión logra vencer parcialmente la condena benjaminiana de la mudez.

12 Hay una cierta contradicción en esta identificación con la guerra, la que Freud explica mediante el fenómeno de la identificación narcisista: "La identificación narcisista con el objeto se convierte entonces en el sustituto de la investidura de amor, lo cual trae por resultado que el vínculo de amor no deba resignarse a pesar del conflicto" (247). Esta identificación que en el caso que tratamos se produce mediante el lenguaje estetizante "es el primer modo, ambivalente en su expresión, como el yo distingue a un objeto. Querría incorporárselo, en verdad, por la vía de la devoración, de acuerdo con la fase oral o canibálica del desrrollo libidinal” (247). 
Mencionábamos al comienzo la notoria diferencia -relativa al lirismo-, entre estos poemas y el resto de la poesía harriana. A manera de hipótesis planteamos que ésta se origina en la distancia que media entre el acontecimiento traumático (la Segunda Guerra Mundial) y la escritura. Una segunda distancia se genera cuando el poeta es mediador de la voz del soldado padrastro Erwin Kopp. Se convierte en un portavoz de otra que sí ha vivido la experiencia en cuestión. Estas dos "mediaciones", la distancia temporal y la voz del padrastro impregnan la poesía y permiten la "elaboración" del duelo. La hipótesis se tiende a comprobar en el poemario que analizaremos a continuación ("Balada del condenado de Oklahoma") en el que el trauma de la guerra vuelve a los tonos previos, con más violencia verbal y obscenidad. Este regreso a la estética más recurrente se debería a la cercanía de los acontecimientos: la Guerra del Golfo.

\section{2. "BALADA DEL CONDENADO DE OKLAHOMA": ELABORACIÓN DE LA IMAGINACIÓN Y EL EROTISMO}

"Balada del condenado de Oklahoma" consta de seis poemas relativamente largos más un epílogo, y tiene como núcleo temático la ejecución del joven veterano de la Primera Guerra del Golfo, Timothy Mc Veigh ${ }^{13}$. Es como todos los poemarios de Harris una narración. Ahora bien, hay un evidente distanciamiento de la estética utilizada para "Encuentros al fin de la batalla", la que se centraba en una sola voz. Muy por el contrario, ahora tenemos un choque de perspectivas que viene a fragmentar el acontecimiento como un prisma. Pues precisamente de lo que se trata aquí es de cuestionar el estatuto de la guerra en cuanto experiencia. En el centro del poemario, y actuando como bisagra, está la provocativa frase de Jean Baudrillard: "Dice Jean Baudrillard que la $1^{\text {a }}$ Guerra del Golfo no ha tenido lugar" (77). El poemario parece girar sobre esta tesis ${ }^{14}$ mediante el choque de dos voces: la de un mirón-Voyeur que

13 Timothy Mc Veigh participó en el año 1991 en la Guerra del Golfo Pérsico y recibió condecoraciones por su comportamiento destacado como soldado. Posteriormente, en el año 1995, realiza un atentado terrorista a un edificio del FBI en el que mueren 168 personas, entre ellos niños, y quedan 850 heridos. Es condenado a pena de muerte por inyección letal y muere el 11 de junio del 2001.

14 Se encuentra en la obra La guerra del Golfo no ha tenido lugar de Jean Baudrillard. Se trata de un ensayo de 102 páginas en las que se aborda críticamente el nexo entre la guerra y los medios de comunicación. 
espera e imagina la ejecución del sentenciado y la del propio joven que narra su experiencia en el desierto. Las voces son discordantes y no se llega a una visión unitaria de la guerra en cuestión. Si en una primera lectura pareciera que la postura del mirón confirma la tesis baudrilliana y la del soldado la revoca, nos percatamos de que en realidad se trata de tres lecturas distintas del "acontecimiento" de la guerra. La simultaneidad de las tres "lecturas" es lo que, en definitiva, eleva la guerra a categoría de trauma, entendido como la imposibilidad de asimilar al acontecimiento y su dificultad para representarlo. La Guerra del Golfo es una experiencia no asimilada y que dificulta las categorías mediante las cuales sería posible someterla a la narración.

La estructura del poemario en relación con las tres focalizaciones es la de un trenzado. Se abre con un largo poema del mirón para seguir con un fuerte distanciamiento que da paso a la tesis intelectualista de Baudrillard. Los poemas III, IV y V son la contrapartida con la voz del soldado que va a morir y que narra su experiencia. El poema seis nos devuelve a la voz inicial del mirón mediante la que "accedemos" a la muerte del soldado. El epígrafe que no lleva numeración podemos considerarlo quizás una cuarta focalización: de hecho, no es la mano de Harris, sino un texto periodístico referencial y que da cuenta de los últimos momentos del sentenciado. En relación con las otras tres voces: mirón, teórico y soldado, es la más "externa" e implicaría un anhelo de focalización cero o de ausencia de sujeto en el discurso. Veamos las tres focalizaciones primero por separado y luego podremos establecer los nexos pertinentes.

Focalización del mirón-Voyeur: el largo poema inicial nos sitúa en el especial estado anímico de la espera. Un sujeto x espera la hora de la muerte del soldado, todo gira en torno a ese segundo en que se sabe, a ciencia cierta, que McVeigh morirá. Ahora bien, esa única certeza, y que de hecho se escabulle a lo largo de todo el poemario y actúa como un signo vacio barthiano, está rodeada, por así decirlo, de incertidumbres. El sujeto que espera el acontecimiento fatal no tiene el estatuto de deudo y por lo tanto no podrá presenciar la ejecución por circuito cerrado de cámaras como los familiares de las víctimas. La situación es quizás más inquietante en la medida en que se espera un acontecimiento que no se podrá presenciar; aunque, los deudos, dicho sea de paso, tampoco, ya que solo acceden a la "transmisión" o "representación": "conmigo y en la misma espera/me han de acompañar los deudos de las víctimas de Oklahoma,/acongojados,/ silenciosos,/ destrozados en su furia,/ castillos de arena azotados por el otro simún,/atisbando como yo, por la ventana al departamento vecino, el circuito cerrado de pantallas 
que reproducirá/ a escala miniaturizada/ la hora de la muerte fijada por los minuteros/ del gran reloj federal" (71-72). Dos problemas surgen de estas aproximaciones: primero, si el sujeto no es pariente ni del soldado ni de sus víctimas, ¿cuál es su estatuto en relación con esa muerte que está por advenir? Dicho de otro modo, ¿qué le liga a esa muerte que no le pertenece ni le incumbe directamente? Y dos: ¿qué tipo de "experiencia" tiene de ella, si no la puede presenciar? Es la problemática del sujeto moderno, tal y como Giorgio Agamben sostiene en la siguiente cita: "El hombre moderno vuelve a la noche a su casa extenuado por un fárrago de acontecimientos -divertidos o tediosos, insólitos o comunes, atroces o placenteros- sin que ninguno de ellos se haya convertido en experiencia" (2007:8). Retomando la primera pregunta, lo central es el estado anímico de la espera que "sujeta" al sujeto a lo por venir y lo pone en un estado de inacción. Es decir, el sujeto se cierra para otras actividades que no estén ligadas con el ajusticiamiento: "He seguido pacientemente el decurso/ de los minuteros de la muerte,/ siempre implacables, de izquierda a derecha,/como quién espera el Año Nuevo o la Pascua de la Resurrección (...) debo confesar que no he dormido, /como no dormí esperando ver al hombre dando saltitos tullidos/ en la luna,/ o las esperanzas deshechas sobre una cancha de tenis/ en la que ahora ruedan solo hojas otoñales,/marchitos deudos de la derrota deportiva" (72). Se desprende de los versos que el estatuto del sujeto en relación con el acontecimiento no es ni el de deudo ni familiar, sino el de "espectador". Ahora bien, el término espectador con su respectivo binomio espectáculo no se ajusta cien por ciento. En parte por el gesto típicamente posmodernista, y que se encuentra ya como rasgo en la escritura de Harris, de poner en un mismo plano ontológico diversos acontecimientos. El sujeto-espectador espera del mismo modo acontecimientos que sabemos son de naturaleza disímil: Año Nuevo, Pascua de Resurrección, la llegada a la luna, un partido de tenis. La reiteración del comparativo "como" da cuenta de esta falsa operación de sinonimia: la espera no es igual, no es nunca igual, mas se da cuenta de un vínculo que es el que interesa resaltar. Se está frente a la muerte por venir del mismo modo o de un modo similar al que se está frente a festividades religiosas, eventos deportivos o avances científicos tecnológicos. Este sujetoespectador tan particular queda fuera del acontecimiento, no es un agente del mismo. Pero, decíamos que el término espectador no es el que más se ajusta y esto es así porque el sujeto se niega a ser solo un espectador y anhela un cierto grado de participación en el acontecimiento. Dos "actividades" vendrán a superponerse a la del mero espectador: la imaginación y el erotismo. 
Como el acontecimiento en sí (el ajusticiamiento del soldado) se le escapa, el sujeto buscará enconadamente zonas de resistencia para acceder a una "experiencia" más legítima. Entendiendo por "experiencia" una Erfahrung, es decir, una experiencia relativamente integrada. El sujeto echa a andar una maquinaria de desplazamientos voluntariosos en los que establece sinonimias que le permitirían satisfacer mayormente la interdicción que le pesa como espectador. La actividad de mirón se sugiere primero tímidamente, los deudos se encontrarían "atisbando, como yo, por la ventana el departamento vecino,/ el circuito cerrado de pantallas" (71). El mirón reemplaza las pantallas de circuito cerrado por la visión de la ventana del departamento vecino. ¿Qué ve ahora en vez de la muerte del joven?: "el cuerpo de la muchacha del departamento vecino, se distiende como una anémona borracha bajo el agua salada" (72). Mas el cuerpo de la muchacha no es solo el cuerpo de la muchacha, ya que en el verso siguiente leemos: "el cuerpo del condenado de la masacre de Oklahoma, se distiende como una anémona impávida bajo la luz implacable/ de un foco neutro" (71). Así, por actividad metafórica del mirón, muchacha y condenado se aúnan. A esta primera operación se suma la imaginación que llena los vacíos: "yo no tengo circuito cerrado/para ver el ajusticiamiento (...) solo puedo imaginar; pero/ ¿qué vio, olió, sufrió,/ que condenó al condenado entre la arena inexistente, sobre la superficie vacua de la nada que rodeaba Bagdad?" (72-73). Las preguntas del mirón rebasan el estatuto de mero espectador, ya que apuntan a recuperar o reconstituir, aunque vicariamente, una "experiencia". La apelación a los sentidos se lee como un intento de "incorporar" o hacer asible la inmaterialidad del espectáculo televisivo. El cambio de espectador a "imaginador", que tiene como objetivo el cambio a su vez de acontecimiento-espectáculo a acontecimientoexperiencia, no deja de conllevar sus riesgos. El sujeto va tan lejos que incluso intenta una "explicación", quiere entender el porqué de las acciones del otro: "Eso que vio, olió, pensó, murmuró, soñó/ i- tuvo un momento de sopor?- /tragó por cantidades el simún,/todo eso/ lo llevó a declarar culpable a su Patria, sin remisión,/el guerrero condecoró a su vez con 160 almas,/ (...) /a una muerte sin piedad ni dolor; /300 heridos-mutilados, llagados, cercenados, tuertos" (73). Es evidente que las operaciones que realiza el sujeto imaginador no son pasivas, por el contrario, se asumen posturas éticas incluso difíciles de sostener. Se llega casi a una "identificación" con el condenado. $\mathrm{Si}$ el espectador es el que está "fuera del acontecimiento", lo que implica un empobrecimiento en el plano de la experiencia, hay aquí un intento por volver a la experiencia, aunque vicaria y sustituta. Hay identificaciones y 
proyecciones típicas de acontecimientos traumáticos teñidos con nuevos semas. Entonces, si empezábamos sugiriendo el estatuto de "espectador" para este sujeto que no ha vivido directamente el trauma en cuestión, ya que no es ni pariente, ni deudo, ni soldado, la lectura va mostrando cómo en realidad se trata de un estatuto mucho más complejo y que opone resistencias al binomio simplista espectador-espectáculo. El sujeto que hemos denominado como "mirón-imaginador" eleva este acontecimiento a categoría especial: "He esperado este acontecimiento como/ quien espera un eclipse,/ el paso de un cometa/el nacimiento de un astro: una muerte por inyección letal: / ¿cuál es la diferencia en el concierto del cosmos?” (74). Una vez más, la homologación de acontecimientos dispares ontológicamente trae, en este caso, no el efecto posmoderno de una banalización, sino precisamente una mayor reflexión y cuestionamiento. Ya podemos claramente abandonar por inapropiado el término espectador, puesto que no corresponde al nivel de participación y postura crítica que nos muestra esta voz.

Ahora entroncamos con el segundo elemento mediante el cual el sujeto ofrece resistencia a su reducción de mero espectador (la primera era la imaginación), nos referimos al deseo o erotismo. Con la inclusión del elemento erótico y la pulsión del deseo, retomamos las dos preguntas iniciales: qué liga al sujeto a este acontecimiento y si hay o no experiencia. La actividad del mirón se suma a la del "imaginador": "Como por mi ventana solo veo la ventana de la muchacha/ a la que suelo atisbar en su semidesnudez,/ a la hora nona,/ noche a noche,/ pasearse enfundada en un body blanco sobre su cuerpo rosa,/en esa redundante y erótica superposición, imagino que el héroe de la Batalla del Desierto/ cierra los ojos para regresar/ a los arenales y caminar por sobre las dunas, apaciguadas,/ inmóviles, pardas en toda su conmiseración,/ para pensar que es al Otro,/ al traidor, /al que le invade el líquido letal- el veneno-/ por las ramificaciones entreveradas de sus venas" (75). Por primera vez se expresa claramente una de las paradojas del acontecimiento en cuestión: el soldado Timothy McVeigh es tan héroe como traidor. Héroe en la Guerra del Golfo y traidor en su acto posterior y horrendo de asesinar a inocentes. Este sujeto encarna en sí la típica paradoja del acontecimiento posmodernista $^{15}$ : ¿cómo se puede ser héroe y traidor al mismo tiempo?

15 Seguimos a Hayden White, en El texto histórico como artefacto literario, quien distingue un cambio radical en la lógica de los acontecimientos a partir del siglo XX. El acontecimiento presenta una resistencia a las categorías y las convenciones heredadas para 
¿Cómo se puede condenar a muerte por inyección letal al mismo sujeto que antes fue condecorado? ¿Una acción es origen de la otra? ¿Es el crimen de McVeigh resultado de su participación en la Guerra del Golfo? ¿Es víctima o victimario? Todas estas preguntas socavan el acontecimiento y lo vuelven inasible, inexplicable y, en definitiva, inenarrable ${ }^{16}$. Lo que se lee en los versos recién expuestos es una disociación, pues el sujeto mirón-imaginador opta por disociar al héroe del traidor: quién muere es solo el traidor, y el soldado regresa a su desierto-paraíso en el que se salva en su integridad.

Pero volvamos a nuestro punto, el del sujeto erótico o deseador y el estatuto del acontecimiento en cuanto experiencia que va más allá del espectador. En el poema VI, luego de pasar por la focalización del teórico y por la del soldado, vuelve la del mirón. Mirón que continúa su actividad imaginativa casi identificatoria y reproduce el momento de la muerte que le es vedada: "El mecanismo de la muerte se ha activado/ a esta hora encapuchada de la noche. / El joven veterano siente, ahora, /el líquido espeso de la Piedad/ entrando por su torrente sanguíneo/entreverando letal con el odio de los deudos, que ven la ejecución por circuito cerrado" (86). A este "espectáculo" imaginado el mirón superpondrá el deseo: "Entonces, atisbo, como buen mirón de la muerte,/ al departamento del frente y la muchacha/ se ha quitado el body y deambula desnuda por su habitación" (86). Ahora el sujeto mirón-imaginador-deseante sufrirá un ataque de duda posmodernista, en el que la existencia misma del acontecimiento y de la realidad es puesta en duda, como si volviera a acechar la posibilidad de reducir la experiencia al mero binomio espectáculo/espectador: "Dudo si existe./ Dudo si existe la desnudez perfecta,/ sin mácula./Dudo si existe esta especie de erección./ Dudo si existe esta

asignarle un sentido: "no se prestan a explicación en términos de categorías suscritas por la historiografía humanista tradicional, que exhibe la actividad de los agentes humanos como si éstos fuesen de algún modo completamente conscientes de sus acciones, y capaces de discriminar claramente entre las causas de los acontecimientos y sus efectos" (227).

16 Y sin embargo, de la narración o de la capacidad del sujeto de elaborar un discurso coherente depende la superación del trauma o lo que hemos denominado desde el comienzo como elaboración. Como sostiene LaCapra: "La narración, incluyendo la narrativa experimental, desempeña un papel importante aquí, sobre todo en cuanto a los síntomas postraumáticos de acontecimientos y experiencias límites, pero lo mismo puede decirse de otras formas como la poesía o el ensayo y los modos preformativos como el ritual, el canto y la danza". En la misma línea de pensamiento se encuentran Paul Ricouer (Tiempo y narración), Hannah Arendt (La condición humana) y Primo Levi (Si esto es un hombre). 
noche estrellada,/ lejos de Bagdad y USA./ Dudo si existe Santiago de Chile, Sudamérica,/ este finis terrae desde donde profiero mi asco, mi ascua"(86). El sujeto se ve afectado por la naturaleza equívoca de los acontecimientos, y sin embargo, su respuesta será el acto autoerótico que lo afirma y centra: "Si tan solo la muchacha mirara hacia mi departamento/dudoso y viera que me masturbo/mirando su cuerpo de cisne urbano" (86-87). Mediante este acto, el sujeto "ejecuta" una "experiencia substituta" a la del ejecutado: "mis espasmos y mis gestos/deben ser a imagen y semejanza/ del héroe de la Operación Tormenta del Desierto,/ que ahora ya ha muerto sin saber siquiera/ si existió entre este mundo y el Otro" (87). Por sobre la duda generalizada, por sobre las puestas en abismos y peligrosas identificaciones de este sujeto pareciera subyacer una remisión a un sentido. Ya no un "signo vacío", sino una "opacidad", que los acontecimientos vuelvan a ser experiencias más que espectáculos y los sujetos más que espectadores: "Espejo de sus espejismos y mi espejo deseante/ de la muchacha en body/espejo de los arenales sin edad y tu propio espejo de Creador: la opacidad" (87). El sujeto está consciente de que su imaginación y su autoerotismo no son más que resistencias que no logran cambiar totalmente la naturaleza equívoca de los acontecimientos y que el sentido último, la "opacidad", que ya no genera más refracciones, está en un sujeto a-histórico. Ese sujeto a-histórico solo entra al tejido del poema desde la invocación-interpelación: “¿No es así, Dios, viejo cuervo?” (87). Más allá de la real posibilidad de experimentar un acontecimiento como la Guerra del Golfo y la sentencia de muerte de un soldado, lo que nos interesa en este recorrido es mostrar cómo el sujeto genera técnicas de resistencia y se niega a reducir su nivel de participación al de mero espectador. Según Agamben, nos hemos quedado sin experiencias ya que éstas ocurren fuera de nosotros ${ }^{17}$, la actividad erótica es un modo de hacer que la experiencia pase por el cuerpo.

Focalización del teórico: al poema del "sujeto-imaginador-mirón-deseante" le sigue el poema que representa la focalización de la teoría. Es decir, los acontecimientos son traducidos a un metalenguaje que pretende fijarlos,

17 "De allí la desaparición de la máxima y el proverbio, que eran las formas en que la experiencia se situaba como autoridad. El eslogan que los ha reemplazado es el proverbio de una humanidad que ha perdido la experiencia. Lo cual no significa que hoy ya no existen experiencias. Pero éstas se efectúan fuera del hombre. Y curiosamente el hombre se queda contemplándolas con alivio" (Agamben 10). 
conceptualizarlos. Es un brusco giro hacia un lenguaje técnico, evasivo, reductor y que pretende dar cuenta objetivamente de un fenómeno. En este caso, la focalización teórica se hace mediante las citas o paráfrasis a los postulados de Baudrillard: "Dice Jean Baudrillard que la $1^{\text {a }}$ Guerra del Golfo no ha tenido lugar. Fue una farsa bien urdida por los estrategas del Pentágono" (77). No interesa aquí entrar a dilucidar el planteamiento complejo que se encuentra en el ensayo del teórico francés, sino distinguir los conceptos que se vierten en el poema. Harris toma de la teoría conceptos como "realidad virtual", "imagen", "holograma", etc. El núcleo es la oposición binaria entre realidad-deseo-carne, versus virtualidad-Nada-No-deseo. Mediante esta nomenclatura, el estatuto de la guerra en cuanto acontecimiento es puesto en duda: "una guerra hecha de perversiones binarias/y no de cuerpos trozados,/ de sangre vampirizada por las imágenes y no por la arena del desierto:/ ha cambiado todo el paradigma de la sensibilidad" (77). Lo que está en juego en esta guerra -a diferencia de la Segunda Guerra Mundial en que, como vimos, peligraba un paisaje cultural- es la desaparición del acontecimiento mismo producto de la intromisión de los medios de comunicación, en especial la televisión. Decíamos que este poema actuaba como bisagra, ya que media entre la focalización del sujeto mirón -la que se resiste al juego del espectáculo, es decir, que no coincide con la focalización del teórico-, y la del soldado que viene directamente a oponerse a la teoría.

Focalización del héroe-traidor Timothy McVeigh: el poema III se abre con el adversativo "Pero", que se lee como una negación al discurso teórico. Al no-deseo, a la ausencia de cuerpo y pulcritud de la guerra televisada, se contrapone el cuerpo y la sangre: "Pero yo nací de vientre de mujer (...)./ Emergí de una gruta húmeda y sanguinolenta, viva, latiente" (79). El origen del héroe como hijo de mujer lo carga de los semas de vida y de corporalidad. A la guerra en general se le antepone un "yo" concreto con nombre y apellido, con su contexto familiar e histórico que lo dota de una identidad, la misma identidad que los mass media quitan: "Nací en los puertos de New York, USA. /Soy anglosajón y de los del Klan" (79). Es decir, la teoría y la supuesta no existencia de la guerra es rebatida con la más vieja y tradicional de las armas: la biografía, contar una historia. En esa historia irá apareciendo, como lo postula Ricoeur ${ }^{18}$, tanto el sujeto de la acción como la acción misma, es decir,

18 Paul Ricoeur elabora en su trilogía Tiempo y narración una compleja teoría sobre los lazos entre narración e identidad (en parte hemos expuesto sus conceptos en la introducción 
la guerra. Mediante esta narración se quiere dar existencia al acontecimiento negado. Los tres poemas del soldado posteriormente condenado devuelven el "cuerpo" al acontecimiento de la guerra, esto sobre todo mediante un lenguaje obsceno y que apunta a metáforas sexuales. Como afirmando que la Guerra del Golfo sí ha tenido lugar: "nadie me va a convencer de que no estuve allí (...) Cómo en ásperas jornadas soporté las duras travesías, / la furia del águila/ que llevo tatuada en mi pecho/ junto a un demente Snoopy, / en los brillantes comandos computarizados de mi tanque,/ en el horrendo desierto embravecido,/ enfilando el falo de hierro de mi cañón/ a la vanguardia de la Operación Tormenta del Desierto" (81). Así, en estos poemas se empieza a mostrar una guerra incorporada, que ha pasado a ser parte del cuerpo del sujeto y no meros hologramas e imágenes. Esto sobre todo mediante las alusiones físico sexuales: el falo es el cañón del tanque, la pertenencia a la patria se lleva en la piel mediante el tatuaje, la cultura en la presencia del personaje Snoopy. Sigue la demostración, mediante experiencias corporales, de que la guerra ha tenido lugar: "Heladas a causa del frío, como higos negros, mis bolas estaban entumecidas por la escarcha de la noche/ del desierto de Bagdad (...)" (82). Las experiencias se centran en respuestas básicas de todo ser humano: hambre, frío, miedo: "Escalofríos y diarrea me producían los chirridos de las orugas/ del tanque pisando minas de poca profundidad: suspiros de impaciencia/desgarraban el águila tatuada en mi pecho y el hambre me hacía alucinar donas y hamburguesas, en un pleno orgasmo gástrico,/hot-dogs emergiendo holográficos entre la arenisca, / y chicas pin up de autocines derramando en mi boca sedienta/ pop-corns sangrientos" (82). La enumeración de los pesares del soldado y su cuerpo va más allá del sujeto individual y se convierte por extensión y mediante la concreta mención a la cultura popular (hot dogs, pop corn, etc.), en el soldado norteamericano medio. Después de esta enumeración solo cabe una lectura-la irónica- de los siguientes versos: "suspendido en una guerra inexistente,/ en

de la cual forma parte este artículo). Para Ricoeur, toda narración es explicación en la medida en que adviene en su lectura una comprensión tanto del "porqué" como del "qué". Junto a esto el sujeto logra una comprensión de sí mismo: "veo en las tramas que inventamos el medio privilegiado por el que reconfiguramos nuestra experiencia temporal confusa, informe y, en el límite, muda" (34). Vuelve a resonar la sentencia benjaminiana de la mudez. Ricoeur se sitúa en el polo opuesto, ya que afirmará por sobre todo la primacía de la narración. Y es esto también lo que hallamos en el poemario de Harris. 
un tanque inexistente,/ rodeado de clamores inexistentes,/ de heridos de ambos bandos inexistentes, / de inexistente arena, / de inexistentes misiles como auroras boreales virtuales,/ de inexistente sangre, / de inexistente miedo,/ de inexistente angustia,/ de héroes inexistentes" (83). La larga enumeración de "inexistencias" actúa de hecho como una afirmación de las mismas. Lo único que empaña y que viene a poner en duda los acontecimientos es la inevitable presencia de la muerte, nos referimos a la condena a morir por inyección letal. Es decir, la guerra pierde esencia y fuerza en la medida en que el yo se aproxima a la hora de su sentencia. Pero aquí podemos abogar ¿no es acaso siempre así, no pierde toda vida su presencia en la medida en que se acerca la muerte? Es así como el soldado termina por afirmar "Lo único real será mi muerte, Dios, puto cuervo. Y frente a eso el Universo es solo irrelevancia" (83). No es que en los últimos momentos el soldado parezca apoyar la postura de la teoría y negar el que la guerra haya tenido lugar, sino que el único acontecimiento sobre el cual se tiene certeza es la propia muerte.

Las tres focalizaciones que hemos perfilado se desmontan y entran en choque la una con la otra. La "teoría" que pareciera ser neutral y objetiva, ya que no posee sujeto que la sostenga -Baudrillard es solo un nombre, no un sujeto-, al final resulta ser la que menos resiste. Se ve socavada por las experiencias del deseo y de la imaginación, por un lado y, por otro, por el hincapié en la corporeidad de la experiencia de la guerra. Sin embargo, al final, tanto en los poemas del sujeto mirón como en los del soldado, la experiencia de la muerte cobra protagonismo. Se "roba la película", por seguir con los términos mediáticos. La muerte es el acontecimiento por excelencia, éste no puede ser robado ni por los mass media ni por la cultura del binomio espectador-espectáculo.

Focalización del epígrafe o periodística: el texto fue extraído literalmente de una reseña de la BBC sobre Mc Veigh y no se nos advierte que en "realidad" es una larga cita periodística. Está puesto al final como último poema y se debe entonces leer como cierre al conjunto cuando la ejecución ya ha sido llevada a cabo. La focalización es la más externa de todas, ya que se da el informe del psiquiatra y el de los abogados. Y, sin embargo, la nota periodística no hace más que traer confusión sobre los acontecimientos, entra nuevamente en choque con lo que sabemos: "Después de examinarlo en la cárcel de Terre Haute, en Indiana, el psiquiatra John Smith concluyó que el recluso 12076-064 era una persona decente que se llenó de rabia a tal punto que cometió este acto violento y terrible" (88). El discurso psiquiátrico no ayuda a entender el porqué de los actos de Mc Veigh, solo lo llenan de más 
preguntas: ¿Qué es la decencia? ¿Somos todos capaces de estos actos? Así, el último poema y que corresponde a la focalización periodística, no dice casi nada, o más bien, pone en evidencia nuestra ineptitud para entender. Antes de morir, el ejecutado habría recitado los versos de un poeta inglés, versos que nuevamente nos sumergen en un mar de dudas: "No importa cuán angosta sea la puerta/ Ni cuán lleno de castigos esté el pergamino/ Yo soy el dueño de mi destino/ Yo soy el capitán de mi alma” (88). Tanto el juicio del psiquiatra como los versos están "puestos ahí", como si hablaran por sí mismos. Lo cierto es que es todo lo contrario, y al lector se le abandona a la incertidumbre y al ejercicio de la interpretación antojadiza. Esta última focalización es la menos asible ya que no hay un sujeto claro que la asuma y, por lo mismo, cubre las posturas anteriores de duda y relativismo.

Recapitulando, el recurso a cuatro focalizaciones distintas e incluso antagónicas, incluido el recurso de poner un texto extraído de internet extrapoético, no hace más que revelar la complejidad del acontecimiento de la guerra. En este caso, la Guerra del Golfo, la que se fractura en varias voces y sigue siendo para el lector, al final, inasible. Se observa una especie de fascinación fetichista con el acontecimiento traumático, sobre todo en el caso del sujeto mirón. Sin embargo, la fijación, al no estar exenta de una postura crítica, se puede considerar como una elaboración. El sujeto elabora la muerte del condenado y la transfiere a su deseo erótico. En la focalización del propio soldado que ha experimentado el trauma de la guerra, su lenguaje plagado de metáforas corporales y sexuales indica ciertamente una elaboración y no una mera reactuación. La inclusión del juicio de Baudrillard y el diálogo intratextual, que se abre sobre todo con los poemas centrados en la voz del soldado, también se adscriben a un trabajo de elaboración. El conjunto total de "Balada del condenado de Oklahoma" se constituye en un trabajo ${ }^{19}$ sobre la Guerra del Golfo, sin llegar, eso sí, a conclusiones definitivas. Esto se condice de hecho con la estructura del trauma, entendida como una herida abierta que periódicamente vuelve y demanda al sujeto nuevas elaboraciones.

El análisis llevado a cabo en "Encuentros al fin de la batalla" y "Balada del condenado de Oklahoma" -poemarios tan distintos entre sí, por su tono y

19 Nos gusta más el término trabajo que el de elaboración, ya que se apega más a la semántica del original alemán de Freud, "durcharbeiten”. Y, al mismo tiempo, alude al trabajo de la escritura. 
por la distancia entre las guerras- revela, sin embargo, una misma búsqueda por elaborar el acontecimiento que pone en jaque al sujeto. En el primer caso, se oscila entre la melancolía y el duelo y; en el segundo, se ofrecen múltiples resistencias para no ser un mero espectador. Así, la poesía de Harris nos habla de la posibilidad de supervivencia de un sujeto más allá o a pesar del acontecimiento traumático.

\section{BIBLIOGRAFÍA}

Agamben, Giorgio. Infancia e historia. Buenos Aires: Adriana Hidalgo, 2007.

Arendt, Hannah. La condición humana. Barcelona: Paidós, 2001.

Bachelard, Gastón. La poética del espacio. México: F.C.E., 1975.

Baudrillard, Jean. La guerra del golfo no ha tenido lugar. Barcelona: Anagrama, 2001.

Benjamin, Walter. Discursos interrumpidos I. Madrid: Taurus, 1998. La dialéctica del suspenso. Santiago: LOM, 1996.

Freud, Sigmund. Obras Completas. Amorrortu Editores, BA; tomo XIV, 1986.

Harris, Tomás. Encuentros con hombres oscuros. Santiago:Ril, 2001.

Tridente. Santiago: Ril, 2005.

LaCapra, Dominick. Historia en tránsito. Buenos Aires: F.C.E., 2006.

Escribir la Historia, Escribir el trauma. Buenos Aires: Nueva Visión, 2005.

Levi, Primo. Si esto es un hombre. Barcelona: El Aleph, 2006.

Ricoeur, Paul. Tiempo y narración. I, II y III. México: Siglo XXI, 2004.

Spengler, Oswald. La Decadencia de Occidente. Madrid: Espasa Calpe, 1940.

White, Hayden. El texto histórico como artefacto literario. Barcelona: Paidós, 2003. 